(1)

CrossMark

\title{
The European research collaboration for Children's Interstitial Lung Disease (ChILDEU) ERS Clinical Research Collaboration
}

\author{
Steve Cunningham ${ }^{1}$, Carlee Gilbert ${ }^{2}$ and Nico Schwerk ${ }^{3}$ on behalf of the \\ ChILDEU Clinical Research Collaboration Management Committee ${ }^{4}$
}

\begin{abstract}
Affiliations: ${ }^{1}$ Dept of Child Life and Health, Centre for Inflammation Research, University of Edinburgh, UK. ${ }^{2}$ ChILD Lung Foundation, Wallasey, UK. ${ }^{3}$ Hannover Medical School, Hannover, Germany. ${ }^{4} \mathrm{~A}$ full list of the ChILDEU Clinical Research Collaboration Management Committee can be found at the end of this article.
\end{abstract}

Correspondence: Steve Cunningham, Children's Clinical Research Facility, University of Edinburgh, Dept of Respiratory and Sleep Medicine, Royal Hospital for Sick Children, Sciennes Road, Edinburgh, EH9 1LF, UK. E-mail: steve.cunninghamanhs.net

@ERSpublications

Enhanced clinical, parent, academic and industry engagement in the field of children's interstitial lung diseases will help improve case ascertainment, mechanisms and therapeutic developments for these ultra-rare conditions http://ow.ly/SM0I30mC3Jk

Cite this article as: Cunningham S, Gilbert C, Schwerk N. The European research collaboration for Children's Interstitial Lung Disease (ChILDEU) ERS Clinical Research Collaboration. Eur Respir J 2018; 52 : 1801855 [https://doi.org/10.1183/13993003.01855-2018].

\section{Rationale}

There are over 200 conditions collectively assigned as children's interstitial (or diffuse) lung disease (ChILD), with a prevalence of 1.5 [1] to 3.6 [2] per million children per year. The conditions individually are rare to ultra-rare and are lumped for convenience [3], but studies need larger cohorts for each condition, in order to deliver progress. As most university hospitals see between one and five new ChILD cases each year [4], progress is slow unless international co-operation is in place.

The development of ChILD networks has seen several national database initiatives, including the chILD Foundation in the USA [5] (initiated by Robin Deterding), RespiRare in France [6] (coordinated by Annick Clement) and the Kids Lung Register (www.kids-lung-register.eu) in Germany (organised by Matthias Griese), together with databases in the UK [7] and Australia [1]. The organic development of these initiatives at national level, whilst beneficial, increasingly makes us aware of the limitations of national datasets for the future expansion of ChILD knowledge. In 2013, for the first time, a European Union (EU) 7th Framework Programme (FP7)-funded project developed an international registry, database and biobank: the chILD-EU project (www.childeu.net). The project systematically collated cases of ChILD, provided international peer review, and supported biobanking of radiology, pathology and laboratory samples (including DNA) [8]. In addition, anecdotal use of treatments was reassessed via a Delphi process to provide recommendations for management [8], and patient-reported outcomes were derived [9]. chILD-EU initiatives are bearing fruit, with the publication of larger retrospective series of more frequently occurring ChILD conditions [10, 11]. 
The European Respiratory Society (ERS) call to develop a Clinical Research Collaboration (CRC) [12] was a timely springboard for ChILD, coming toward the end of the EU FP7 funding. The European research collaboration for Children's Interstitial Lung Disease (ChILDEU) CRC commenced in April 2016 within the Paediatric Assembly of the ERS.

Aims

ChILDEU CRC funding enabled us to maintain the momentum created by the FP7 project, but also to consider how best to enhance future opportunities. There were four key aims for ChILDEU: 1) to derive a common international minimum dataset with agreed field terms and descriptors; 2) to enable a wider range of clinicians to recognise, diagnose, manage and support ChILD conditions; 3) to create an international parent/patient partnership to encourage support for ChILD at a local, national and international level; and 4) to encourage and support engagement and investment by academia and industry for ChILD.

\section{Past achievements}

The ChILDEU CRC, recognising the rarity of ChILD conditions and the regulatory and mindset hurdles to the development of a truly global database, has worked to devise a common minimum dataset. At a CRC meeting in Prague in 2017, representatives of the global ChILD database agreed in principle to deliver a commonly preserved minimum dataset with descriptions and fields that are changed only by common international agreement. For the ChILDEU CRC this is continuing work with international and industry collaborators, and progress is being made.

The CRC now delivers free, succinct and accessible educational opportunities for ChILD through webinars. The objectives are to improve diagnosis and management of ChILD [13] within Europe, and also as a global resource [14]. Access is open to all, but with a particular focus on early career trainees. The webinars, hosted by a University of Edinburgh (Edinburgh, UK) platform, are $1 \mathrm{~h}$ in duration with a presentation by an expert in ChILD, and Continuing Professional Development certificates of attendance are provided to attendees. Recordings of the webinars are available at www.klinikum.uni-muenchen.de/ Child-EU/en/crc/webinar-series/index.html.

The ChILDEU CRC has a key aim to develop a greater international reach for parents and children affected by ChILD. Working with the European Lung Foundation (ELF), we have developed an international parent and patient group. The ELF has been instrumental in enabling communication across time zones and providing support in multiple languages. The group have developed, delivered and analysed a survey of patient and parent perspectives of ChILD, informed by 156 participants from 15 countries, with results presented at the ERS International Congress in Paris (France) in September 2018. The group have also, in liaison with the ELF and ChILDEU CRC, developed a ChILD website, containing key information and practical help on the management of ChILD conditions (www.europeanlunginfo.org/child/).

Delivering clinical trials in ChILD presents enormous challenges from both logistic and scientific perspectives: the chILD-EU FP7 randomised controlled trial of hydroxychloroquine in interstitial lung disease (the first randomised controlled trial in ChILD) has been beset by regulatory challenges [13]. Trials of therapeutics to treat individual diseases and resulting pathology (i.e. fibrosis) are in pre-clinical development for ChILD. To support research infrastructure for future trials, the ChILDEU CRC is working to identify clinical outcomes for ChILD interventions. The ChILDEU Register now includes standardised structured observational data of over 600 patients (128 incident and over 500 prevalent cases) [8], and prospective analyses are in progress.

\section{Future plans}

The future for ChILD lies with enhanced case ascertainment and a greater assimilation of knowledge of phenotypes for individual diseases and pathophysiological groups (i.e. fibrotic diseases). The ChILDEU CRC will enhance this capacity through a greater reach of educational opportunities and parental empowerment. The potential of therapeutic options for ChILD will lead to greater clinician engagement. A ChILDEU CRC Translational Science meeting will be held in Edinburgh in June 2019 with this educational aim. The ChILDEU CRC will collaborate with other CRC groups, particularly to explore understanding of genomics through studies of lung expression in paediatric and adult interstitial lung disease (in the ERS Lung Fibrosis Clinical Research Group). The work of parent groups (in liaison with the ELF) has been a highlight so far within the CRC, helping to identify key areas for clinical focus, as described. We will build on these to help deliver a better patient experience across EU countries and language barriers. 


\section{Challenges}

Whilst the ChILD common minimum dataset is agreed in principle across the global database, initiatives that are running in parallel but at a different pace (i.e. the European Reference Network for rare respiratory diseases (ERN-LUNG) database, and pharma initiatives) may cause traction, but do not deflect from the ultimate value of this aim. Rare lung disease in children remains extremely vulnerable to the pressures of competing diseases, particularly in countries with limited resources. The ChILDEU CRC will continue to develop international promotion of ChILD through support of local clinicians and parent groups. Some ChILD genetic conditions could be adaptable to intervention, and enhanced case ascertainment will enable us to develop greater academic and industry engagement. The ChILDEU CRC continues to search for strategies to facilitate genetic testing of children at low cost where there is a high probability of a genetically associated ChILD (i.e. surfactant deficiencies, COPA syndrome (mutations in the COPA gene), SAVI (STING-associated vasculopathy with onset in infancy), etc.), regardless of geography.

For more information on the ChILDEU Clinical Research Collaboration, including how to contribute, contact ChILDEUCRC@ed.ac.uk or see the information for clinicians at www.childeu.net. The European Lung Foundation website at www.europeanlunginfo.org/child gives further information for parents/patients.

Members of the ChILDEU Clinical Research Collaboration Management Committee: Steve Cunningham (Chair), Nico Schwerk (Chair), Carlee Gilbert (patient representative), Andy Bush, Annick Clement, Robin Deterding, Matthias Griese, Adam Jaffe, Fabio Midulla, Deborah Snyder and Jeanette Boyd (European Lung Foundation representative)

Conflict of interest: S. Cunningham reports fees from Boehringer Ingelheim, paid to Edinburgh University for consultancy work, outside the submitted work. C. Gilbert has nothing to disclose. N. Schwerk has nothing to disclose.

Support statement: Funding was received from the European Respiratory Society, grant ERS CRC2015-02 (ChILDEU). Funding information for this article has been deposited with the Crossref Funder Registry.

\section{References}

1 Saddi V, Beggs S, Bennetts B, et al. Childhood interstitial lung diseases in immunocompetent children in Australia and New Zealand: a decade's experience. Orphanet J Rare Dis 2017; 12: 133.

2 Dinwiddie R, Sharief N, Crawford O. Idiopathic interstitial pneumonitis in children: a national survey in the United Kingdom and Ireland. Pediatr Pulmonol 2002; 34: 23-29.

3 Nicholson AG, Bush A. Classification of diffuse lung disease in infants: the reality of groups. Am J Respir Crit Care Med 2007; 176: 1060-1061.

4 Hime NJ, Zurynski Y, Fitzgerald D, et al. Childhood interstitial lung disease: a systematic review. Pediatr Pulmonol 2015; 50: 1383-1392.

5 Deterding RR. Children's interstitial and diffuse lung disease. Progress and future horizons. Ann Am Thorac Soc 2015; 12: 1451-1457.

6 Nathan N, Taam RA, Epaud R, et al. A national internet-linked based database for pediatric interstitial lung diseases: the French network. Orphanet J Rare Dis 2012; 7: 40.

7 Laverty A, Jaffé A, Cunningham S. Establishment of a web-based registry for rare (orphan) pediatric lung diseases in the United Kingdom: the BPOLD registry. Pediatr Pulmonol 2008; 43: 451-456.

8 Bush A, Cunningham S, de Blic J, et al. European protocols for the diagnosis and initial treatment of interstitial lung disease in children. Thorax 2015; 70: 1078-1084.

9 Niemitz M, Schwerk N, Goldbeck L, et al. Development and validation of a health-related quality of life questionnaire for pediatric patients with interstitial lung disease. Pediatr Pulmonol 2018; 53: 954-963.

10 Kröner C, Wittmann T, Reu S, et al. Lung disease caused by ABCA3 mutations. Thorax 2017; 72: 213-220.

11 Rauch D, Wetzke M, Reu S, et al. Persistent tachypnea of infancy. Usual and aberrant. Am J Respir Crit Care Med 2016; 193: 438-447.

12 Brightling C, Genton C, Bill W, et al. ERS Clinical Research Collaborations: underpinning research excellence. Eur Respir J 2018; 52: 1801534.

13 Griese M, Seidl E, Hengst M, et al. International management platform for children's interstitial lung disease (chILD-EU). Thorax 2018; 73: 231-239.

14 Aryan Z, Modaresi M. Paediatric orphan lung diseases in Asia. Lancet Respir Med 2016; 4: 174-175. 